\title{
Barriers and strategies of reporting medical errors in public hospitals in Riyadh city: A survey-study
}

\author{
Ahmed Mohammed Saleh Alduais ${ }^{1,}$ Salah Mogali ${ }^{2,}$ Bader Al Shabrain ${ }^{2,}$ Abdullah Al Enazi ${ }^{2,}$ \\ Fuad Al-awad ${ }^{2}$ \\ ${ }^{I}$ Clinical Linguistics Stream Department of Linguistics, Institute of Social Sciences Ankara University, 06100, \\ Sihhiye, Ankara, Turkey \\ ${ }^{2}$ Department of Health Administration College of Business Administration \\ King Saud University, Riyadh, Kingdom of Saudi Arabia
}

\begin{abstract}
:
Purpose: The aim of this study was to find out the barriers preventing staff from reporting medical errors and identifying the strategies which might encourage the staff reporting the medical errors at Riyadh, Saudi Arabia.

Method: The data was collected using a questionnaire where random sampling was used to represent the hospitals of Riyadh city, a represented sample of 467 clinical staff (physicians, nurses) from 9 different hospitals and above from both males and females. Descriptive analysis and inferential statistics were used to identify the barriers and the strategies towards improvement of medical errors reporting.

Results: There were actually no gender significant differences-Saudi and non-Saudi, physicians and nurses regarding response to barriers and the strategies. There were also no significant differences between types of hospitals regarding barriers and strategies reporting. $r=.482>.05$ and $r=.701>.05$. However, there was a significance difference between age structures regarding the barriers reporting. $r=.000<.05$ where the age range between 31-40 years provided more responses to reporting the barriers than the 41-50 years and 50 and above. There were also significant differences between levels of education regarding the strategies reporting. $r=.012<.05$ where the board provided more response to reporting the barriers than the diploma. Besides, there were significant differences between years of experience regarding the barriers reporting. $r=.000<.05$ where the 0-10 years and 11-20 experience provided more responses to reporting the barriers than both (21-30 years) and (31years and above).

Conclusions: The most common barriers preventing the staff from reporting the medical errors are: fear of being blamed, fear of being punished, difficulty in filling the form, lack of knowledge of what should be reported, medical errors reporting are inadequate, lack procedures on reporting medical errors. On the other hand, the most common strategies improving reporting medical errors are: there should be a clear guidelines and procedures for reporting errors, forms and other documentation should be clear, staff should be trained on reporting medical errors, staff should always be encouraged to report medical errors.
\end{abstract}

Keywords: medical errors reporting; public hospitals; barriers and strategies; public health

\section{Introduction}

Improving patient safety is a priority in relation to health care agenda for nearly all policy and decisionmakers in public health worldwide. 'Healthcare facilities should create a sense of trustworthiness and safety', (Phsj.org, 2014). Besides and despite 'the healthcare systems best efforts; people are injured due to an unorganized and overwhelmed healthcare system', (ibid). The Institute of Medicine's legendary report in (1999) stated 'at least 44,000 people and perhaps as many as 98,000 people die in hospitals each year as a result of a medical error that could have been prevented'.

There are many definition for the term medical error; however, the (Institute of Medicine Report (IOM), 1999) defines a medical error as 'the failure of a planned action to be completed as intended or the use of a wrong plan to achieve an aim'. Another term which will be used in this study is patient safety. It refers to 'the avoidance, prevention and amelioration of adverse outcomes or injuries stemming from the process of health care', (ncbi.nlm.nih.gov, 2014; US National Patient Safety Foundation, 1999).

Actually, 'a medical error can occur in any healthcare setting in the form of an 'adverse drug event, improper transfusion, surgical injuries and wrong site injuries, suicide, restraint-related injury or death, falls, burn, pressure ulcers and mistaken patient identity', (Phsj.org, 2014). Besides, it is 'more likely to develop in an emergency department, an intensive care unit or an operating room' (ibid).

The common types of medical errors 'were hospital infection rate of diagnostic errors, needle or cutting tool injuries and problems related to drug usage which have side effects, (qualitydigest.org, 2014). Some studies 
report that 'the cause of medical error highly was tiredness, increased workload and long working hours', (Alemdar, Dilek, \& Aktas 2013).

'The medical culture that has brought us to the brink of healthcare destruction and distrust is a culture of perfect performance and the mentality of not reporting an error due to fear of disciplinary action', (Phsj.org, 2014). Before the 1990s, 'perfect performance was expected and felt to be achievable through education, professionalism, vigilance and care', (Institute for Safe Medication Practices, 2006). This environment leads to a 'fear of retribution, ranging from undue embarrassment, employment and/or licensure termination, drove errors underground', (Phsj.org, 2014). Because of these 'overarching themes in medicine, we lost an enormous opportunity to learn from our mistakes and grow' (ibid). The mid 1990's 'brought about a change, health care providers were starting to acknowledge 'human fallibility and the impossible task of perfect performance', (ibid).

An estimated 6,000 to 20,000 patients die from medical errors each year, and 10\% of medical law suits were because of medication errors in Taiwan in 2003, (Chiang, Pepper, \& Ginette, 2006; Taiwan Joint Commission on Hospital Accreditation (TJCHA), 2004). Nurses are the front line of defense to intercept and report medication errors.

But the physician also participates in this issue in addition to the nurses. 'Medical errors were starting to be seen as the result of mental slips or lapses, or honest mistakes that were rooted in system, process, technical, or environmental weaknesses that lay dormant in the organization until errors or proactive assessment efforts brought them to light', (Phsj.org, 2014).

This concept was 'labeled (blame free) in the medical world', (Phsj.org, 2014). Blame free had its downfalls; 'it does not confront individuals who willfully make unsafe behavioral choices, knowingly disregarding a substantial and unjustifiable risk that most peers would recognize as being likely to lead to a bad outcome', (Phsj.org, 2014). Despite these setbacks, 'a new medical culture is trying to be developed that uses shared accountability and error reporting without being overly disciplinary, (ibid).

As a result of the increasing medical errors, we need to identify the barriers preventing nurses and physicians from reporting them. Also, we need to specify the possible strategies that could improve and encourage nurses and physicians to report medical errors. Needless to say that 'limited information is available on why these barriers still exist or about methods to overcome these barriers successfully', (Hartnell, 2012). Hartnell continues that 'such information must be obtained before the improvements of patient safety can be realized through lessons learned from the reporting of medication errors', (ibid). Reporting of medical errors will help health personnel and decision makers to:

1. Know how the inhabitance of error-reporting could ultimately result in improving patient care and increasing the patient safety;

2. Help to create a system that ensure reduction of errors in health care organizations; and

3. Decrease the length of patients stay in hospitals and decrease the cost of medication related to medical errors.

On the basis of this, the current study attempts answering the following questions:

1. What are the barriers which prevent nurses and the physicians from reporting medical errors?

2. What are the strategies which could be used to encourage reporting medical errors?

3. What is the relationship between reporting of medical errors (barriers and the strategies) and sociodemographic variables?

\section{Background}

Basically, medication error refer to 'any preventable event that may cause or lead to an inappropriate medication use or patient harm while the medication is in the control of the health care professional, patient, or consumer', (onlinelibrary.wiley.com, 2014; Council of Europe Expert Group on Safe Medication Practices, 2006). It has 'a substantial impact on the health of individuals, organizations and the health care system', (ibid). 'Knowledge of what inhibits reporting', (Hartnell, 2012) could remarkably 'result in improved patient care and safety', (ibid) in Riyadh hospitals in Saudi Arabia.

It includes three parts: 'patient safety and causes of medical errors, barriers and strategies which encourage the nurses and physicians to report the errors', (iatrogenic.org, 2014). There are numerous studies which examined the nature and rate of medication errors and adverse events of these errors.

For instance, consider, Mrayyan's study (2012) who stated that there were few number of studies in relation to medication errors in Jordan. This study 'assessed the reported incidences, causes and reporting of medication errors in ICUs and wards of Jordanian teaching hospitals, using a convenience sample of 212 nurses from four teaching hospitals, utilizing a cross sectional comparative research design', (readperiodicals.com, 2014). The mean of the reported incidence of medication errors for the whole sample was $35 \% ; 36.4 \%$ in ICUs and $33.8 \%$ in wards. "An inaccurate rate of TPN was the most common drug error. Poor quality or damaged medication labels were the most common reported cause of errors. Nurses did not report medication errors 
because they were afraid that they might be subjected to disciplinary actions, (readperiodicals.com, 2014). There were some significant differences between ICUs and wards in the reported clinical scenarios of medication errors, as well as causes and reporting of these errors. 'Medication errors are increasing over the years, which mandate the immediate attention of all healthcare professionals in all clinical settings, (readperiodicals.com, 2014).

Another study by Thomas \& Jourdin (2010) found that 'prevention of medication errors is a long-term process, and this pilot study described the first step at the hospital level', (readperiodicals.com, 2014). The medication error management process developed was blame free and maintained confidentiality. 'It allowed implementation of several corrective actions', (readperiodicals.com, 2014). Although much remains to be performed, this pilot study shows that healthcare professionals understand the importance of medication errors and associated risks in hospital care. Furthermore, "they might be encouraged to declare medication errors more frequently' (ibid). They, thus, 'propose to extend medication errors management process to all medical and surgical departments of the hospital group', (ibid). The researchers believe that this process can be replicated in other hospitals. Finally, 'such a reporting system can be integrated in an institutional education system and be part of the actions aiming at increasing a culture of safety' (readperiodicals.com, 2014).

One more study by Alemdar, (2013) reported that 'nurses mentioned the hospital infection, diagnostic errors, needle or cutting tool injuries as the most common medical errors and fatigue, over work load and long working hours as the most common medical error reasons', (scopemed.org, 2014). The suggestions below quoted from (Alemdar, Dilek, \& Aktas, 2013) are made to prevent medical errors yet keeping saving the patient records regularly and preparing an efficient error reporting system in order to avoid medical errors:

1. To change the health education system and to open branches in nursing education;

2. To have continuous education programs after graduation;

3. To educate nurses according to the features of the services and to warn them about necessary points;

4. To decrease the nurses workload with sufficient staff to ensure having nursing services in desired quantity and quality. Nurses mentioned that one of the potential causes of medical errors is having duties unrelated to their job; and

5. To ensure that the nurses are only responsible for the duties related to their profession in order to decrease errors related to the point mentioned in the previous sentence.

Additionally, Frith, (2012) indicated that 'the incidence and cost of medication errors continues to be a problem requiring solutions', (nursingeconomics.net, 2014). A number of technology strategies have been 'implemented to decrease the number of medication errors including computerized physician order entry, automated medication administration records, and bar coding administration', (nursingeconomics.net, 2014).

However, even with the use of these technologies, 'errors continue to occur' (Ulanimo et al., 2007). 'Health care leaders need to consider not only technology capital investments but also human capital as a strategy to keep patients safe', (nursingeconomics.net, 2014). This study examined the relationship between nurse staffing and medication errors. Findings indicated even a small number of LPNs in staffing can contribute to medication errors. 'Even though using LPNs reduces payroll expenses, the safety of patients could be affected', (nursingeconomics.net, 2014). This study adds to the body of evidence that 'patient care is most safely delivered when there are enough RN care hours and when LPN hours are reduced or eliminated', (ibid). The cost associated with RN hours must be balanced against the cost of an error.

In addition to the above mentioned studies, consider also Maryyan's study, (2007) who explored Jordanian nurses' perceptions about 'medication errors and their related issues'. It was reported that 'only $42.1 \%$ of medication errors were reported to nurse managers using incident reports; indicating under-reporting of medication errors by nurses', (ibid). The rate of medication errors reported is 'increasing over the years which requires immediate interventions. Strategies to reduce or eliminate medication errors are mandated', (ibid).

Besides, Elhence \& Shenoy, (2012) mentioned in their study that in total, 285 transfusion related events were reported during the study period. They added, 'of these, there were four adverse (1.5\%), 10 no harm $(3.5 \%)$ and $271(95 \%)$ near miss events. Incorrect blood component transfusion rate was 1 in 6031 component units', (about.com, 2014). 'ABO incompatible transfusion rate was one in 15,077 component units issued or one in 26,200 PRBC units issued and acute hemolytic transfusion reaction due to ABO incompatible transfusion was 1 in 60,309 component units issued', (ibid). Fifty-three percent of the antecedent near miss events were bedside events. Patient sample handling errors were the single largest category of errors $(\mathrm{n}=94,33$ $\%$ ) followed by errors in labeling and blood component handling and storage in user areas. 'The actual and near miss event data obtained through this initiative provided us with clear evidence about latent defects and critical points in the transfusion process so that corrective and preventive actions could be taken to reduce errors and improve transfusion safety', (about.com, 2014).

Furthermore, Hartnell, MacKinnon, \& Fleming (2011) accounted for understanding and overcoming barriers to medication error reporting in hospitals. They attempted to identify 'incentives, barriers and 
facilitators to encourage medication error reporting as perceived by front-line hospital staff, to understand why certain factors serve as barriers, and to explore how some hospitals have successfully removed barriers', (ibid). Barriers to medication error reporting have been identified as individual, organizational and cultural. The study was conducted on four hospitals and focused groups were designed to identify thoughts on multiple aspects of medication errors from the perspectives of front-line healthcare professionals (e.g. physicians, pharmacists and nurses) and in-depth interviews. 'Major changes of this study to improve the process and improve medication error reporting are not going to occur overnight but will require much deliberation, dedication and resource allocation', (Hartnell, 2012). The study suggests that the small number of positive facilitators suggested by these study participants indicate that 'some fairly simple changes could make a positive difference in medication error reporting at these organizations and others facing similar challenges', (ibid). Specifically, reporting should be made as easy as possible (forms should be accessible and straightforward), people should receive timely feedback about reports submitted, and people should receive up to- date education about all aspects of the medication error reporting process at their hospitals.

Moreover, a study was conducted by the Agency for Healthcare Research and Quality (AHRQ), (2000). Physicians stated that medical-error-reporting systems are inadequate. The study discussed doctors in the U.S. where the 'doctors think the current systems to report and share information about errors is inadequate also to prevent untrue report', (qualitydigest.com, 2014). Actually, the study focused on activate reporting system for medical errors to improve patient safety. The sample of this study was doctors from the U.S. and a survey was used to measure 'how to create error reporting programs that will encourage clinician participation', (qualitydigest.com, 2014). Results reported around 54\% agreeing to the idea that 'medical errors are usually caused by failures of care delivery systems not failures of individuals', (ibid).

Once again, Hashemi, Nasrabadi \& Asghari, (2012) conducted a study assessing the factors associated with reporting nursing errors in Iran. In this study, 'the nurses complained about some factors as inhibitors in reporting the errors which were placed in the barriers category', (biomedcentral.com, 2014). The researchers explored the factors associated with reporting the nursing errors. Some factors associated with nurses, organization, and the nurses' awareness of the incidence and consequences of the error were stated as the main barriers in reporting the errors. The study was conducted in the hospitals allied to Shiraz and Tehran universities of Medical Sciences.Sample of study was around 115 nurses with different experience to focus role of experience in reporting the errors. Results of this study stated that 'professional errors are indicative of flawed systems and indicate the lack of safety culture and poor working conditions for nurses', (biomedcentral.com, 2014). System problems can be prevented through reporting of all types of errors. Besides, 'training the nurses as well as the nursing managers regarding the objectives of error reporting and method of using the information of the occurred errors', (ibid) is suggested in order to improve the patient safety and the quality of care in nursing domains. In this case, patient safety and work safety for nurses are improved.

One more study is by Chiang \& Ginette (2006) assessing the barriers to nurses reporting of medication administration errors in Taiwan. The study described nurses' perceptions of reporting barriers to reporting medication administration errors (MAE) and to examine the relationship between the barriers to MAE reporting and cultural factors and nursing work environment in Taiwan. 'Nurses are the front line of defense to cut off and report medication errors', (Chiang, Pepper, \& Ginette, 2006). Learning from errors by depending 'on voluntary error reporting is the strategy in use to improve medication safety and to modify system vulnerabilities', (Chiang, Pepper, \& Ginette, 2006). Understanding of nurses' perceived barriers to MAE reporting is a primary step to strengthen medication safety. The 'linkage between nursing work environment and medication safety is noticeable', (onlinelibrary.wiley.com, 2014). Nurses can provide safer patient care through quality management and work environment transformation. A mail survey using the total design method. Were used in this study. The sample of study was 727 nurses who received the questionnaires but the retuned were only 597 from the total sample. Findings indicated that 'fear and administrative barriers were the top two perceived barriers to MAE reporting also provide new knowledge for design of medication administration safety practices', (Chiang, Pepper, \& Ginette, 2006) in Taiwan. Overall barriers to MAE reporting in the study hospital were mostly explained by power hierarchy and face-saving concern. Work environment factors such as quality management and peer relations modestly contributed to the barriers. Overall barriers to MAE reporting that were perceived as significant were fear and administrative barriers. 'Building a voluntary reporting system without barriers is one of the first steps', (ibid). According to these findings, 'reducing the power hierarchy and modifying personal attitudes toward MAE reporting', (ibid) are suggested.

The study of McFadden, Stoc, \& Charles, (2006) is also worth-mentioning where they explored strategies for reducing hospital errors. Results showed that there are seven critical strategies for reducing hospital errors based on a case study of four Chicago-area hospitals. These strategies include: '1) partnership with stakeholders, 2) reporting errors free of blame, 3) open discussion of errors, 4) cultural shift, 5) education and training, 6) statistical analysis of data, and 7) system redesign', (openclinical.com, 2014). The relationship between this paper and our is intricate where we examined 'the perceptions of healthcare equality directors 
about the importance of these seven patient safety strategies, the factors that act as barriers, the level of adoption of these strategies, and the benefits resulting from implementation of these strategies', (openclinical.com, 2014).

Again, Anderson \& Ramanujam, (2010) showed in their study that the 'inter organizational systems for sharing data about medication errors have emerged as an important strategy for improving patient safety and are expected to encourage not only voluntary error reporting but also learning from errors', (Choir-ut.nl, 2014). Yet, few studies have examined the 'hypothesized benefits of inter-organizational data sharing', (ibid). The current study examined the 'developmental trends in information reported by hospitals participating in a regional reporting system for medication errors', (ibid). 'A coalition of hospitals in southwestern Pennsylvania, under the auspices of the Pittsburgh Regional Healthcare Initiative (PRHI), implemented a voluntary system for quarterly sharing of information about medication errors', (ibid). Over a 12-monthperiod, 25 hospitals shared information about 17,000medication errors. Using latent growth curve analysis, the researchers examined 'longitudinal trends in the quarterly number of errors and associated corrective actions reported by each hospital', (ibid). Controlling for size, teaching status, and JCAHO accreditation score, for the hospitals as a group, error reporting increased at a statistically significant rate over the four quarters. Moreover, despite significant 'baseline differences among hospitals, error reporting increased at similar rates across hospitals over subsequent quarters', (Choir-ut.nl, 2014). In contrast, the reporting of corrective actions remained unchanged. However, the baseline levels of corrective actions reporting were significantly different across hospitals. 'Although data sharing systems promote error reporting, it is unclear whether they encourage corrective actions', (ibid). Having data sharing been able to promote not just error reporting but also root-cause-analysis and process improvement, 'then the design of the reporting system should emphasize data about these processes as well as errors', (ibid).

Kim \& Jin (2011) also attempted to identify Korean nurses' perceptions of medication errors. The nurses reported that there are accuses for doing a medical errors like advanced drug preparation and administration without rechecking. They also reported that the most of the medical errors occur at the shifting time. They concluded the study by the focus on that they must develop strategies to reduce nurses' fear of punishment and supporting nurses' attitudes in a constructive manner are needed.

Kagan \& Barnoy (2013) conducted a study about organizational safety culture and medical error reporting by Israeli nurses to investigate 'the association between patient safety culture (PSC) and the incidence and reporting rate of medical errors by Israeli nurses', (onlinelibrary.wiley.com, 2014). Findings indicated that 'most nurses encountered medical errors from a daily to a weekly basis', (onlinelibrary.wiley.com, 2014). Of the total sample, $6 \%$ never reported their own errors, while half reported their own errors-rarely or sometimes. 'Senior healthcare executives and managers can make a major impact on safety culture development by creating and promoting a vision and strategy', (ibid) for quality and safety and fostering their employees' motivation to implement improvement programs at the departmental and individual levels.

Pal \& Falzon, (2013) presented World Health Organization (WHO) strategy for collecting safety data in public health programmes focusing on national pharmaco vigilance systems relying on spontaneous reporting. In this case, 'suspected adverse drug reactions (ADRs) are reported to a national coordinating centre by health professionals', (who-umc.org, 2014). McDonald, Matesic, \&Schmidt (2013) who conducted a study in patient safety strategies targeted at diagnostic errors. Results indicated that 'the missed, delayed, or incorrect diagnosis can lead to inappropriate patient care, poor patient outcomes, and increased cost. This systematic review analyzed evaluations of interventions to prevent diagnostic errors', (annals.org, 2014).

Forster, Dervin, \& Martin, (2012) conducted a study towards 'improving patient safety through the systematic evaluation of patient outcomes', (ncbi.nlm.nih.gov, 2014). They reported that the failure to implement patient safety measurement systems has compromised the ability to move the agenda forward. Similar to this study, we are also presenting an overview of how patient safety can be assessed and the strengths and weaknesses of each method along with commenting on some of the possible anticipated consequences.

Currently there is a behavior toward design and implementation of the reporting system like that proposed in Guffey's, Szolnoki, \& Caldwell study, (2011).

By and by and with reference to (Hartnell, 2012) who stated that 'while numerous studies have examined the nature and rate of medication errors and adverse events, few studies have examined the determinants of these errors', in this study, the researchers will explore the causes which prevent the nurses and physicians from reporting the medical errors in addition to exploring the strategies which might encourage the nurses and the physicians to report the errors.

\section{Population and Sampling Population}

II. Methods

The study population consisted of all physicians and nurses in these hospitals: King Khalid Hospital in AL-Kharj, King Mohammed bin Abdul-Aziz, King Saud Chest Diseases Hosptial, Al-Amal Specialist Complex 
Hospital, Yamamah Hospital, King Khalid Eye Specialist Hospital, King Faisal Specialist Hospital and several private clinics.

\section{Sampling procedure}

We used a simple random method.

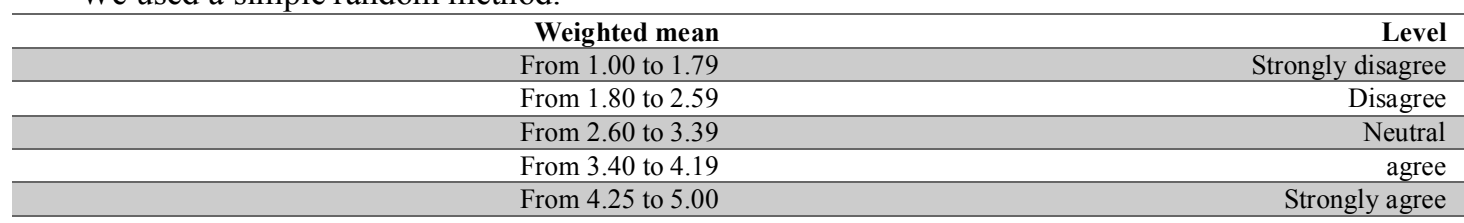

Table (1): Weighted mean attitude

Figure 1:

\begin{tabular}{|c|c|c|c|c|c|c|c|c|}
\hline \multicolumn{9}{|c|}{ Hospitals in Riyadh city } \\
\hline $\begin{array}{c}\text { King } \\
\text { faisal } \\
\text { specialist } \\
\text { hospital }\end{array}$ & $\begin{array}{c}\text { King } \\
\text { khaled } \\
\text { eye } \\
\text { specialist } \\
\text { hospital }\end{array}$ & $\begin{array}{l}\text { king } \\
\text { Khalid } \\
\text { hospit } \\
\text { al in } \\
\text { kharj }\end{array}$ & $\begin{array}{l}\text { several } \\
\text { private } \\
\text { clinics }\end{array}$ & $\begin{array}{c}\text { king } \\
\text { Mohamme } \\
\text { d bin Abdul } \\
\text { Aziz } \\
\text { hospital }\end{array}$ & $\begin{array}{c}\text { Yamamah } \\
\text { hospital }\end{array}$ & $\begin{array}{l}\text { Imam } \\
\text { Abdul } \\
\text { Rahman } \\
\text { Al-Faisal } \\
\text { hospital }\end{array}$ & $\begin{array}{l}\text { King Saud } \\
\text { Chest } \\
\text { Diseases } \\
\text { hospital }\end{array}$ & $\begin{array}{l}\text { Al Amal } \\
\text { Specialist } \\
\text { Complex } \\
\text { hospital }\end{array}$ \\
\hline
\end{tabular}

\section{Measures}

\section{Questionnaire}

The survey instrument used in this study is a questionnaire which was developed by the researchers.

The questionnaire used Likert's scale scale and consists of 3 sections:

- Section 1: asks about type of hospital and socio-demographic information.

- Section 2: asks about barriers that prevent reporting of medical errors.

- Section 3: asks about strategies that could improve reporting of medical errors.

\section{Questionnaire validity and reliability}

To assure the validity, the following procedures were conducted. Firstly, review was made of the relevant literature and the previous instruments were examined to develop drafts. Secondly, the questionnaire was given to professors of health care administration to judge it. Reliability was measured by using Cronbachalpha tool.

\begin{tabular}{ll}
\hline Reliability Statistics of barriers & \\
\hline Cronbach Alpha & N of Items \\
\hline .848 & 14 \\
\hline & \\
\hline Reliability Statistics of strategies: & N of Items \\
\hline Cronbach Alpha & 8 \\
\hline .828 & \\
\hline
\end{tabular}

\section{Research design}

The current study follows a survey-study approach and method design. It attempted reaching a certain description for the level of the problems which can be explored and investigated further using another and/or other research designs.

\section{Procedure}

Data was collected by the researchers who handed the questionnaire forms to the managers of the identified hospitals who in turn submitted to both physicians and nurses in their own hospitals. The data collection was during office hours from 8 am to $2 \mathrm{pm}$. An average of 5 minutes was required to complete the instrument. A total of 467 of 550 (84.9\%) questionnaire forms were returned. Nearly 56 questionnaire forms were not returned. Out of 550 forms, there were 27 uncompleted (misused items). The response rate was $84.9 \%$. 
This study was confined to the physicians and nurses in King Khalid Hospital,Al-Kharj, King Mohammed bin Abdul Aziz, King Saud Chest Diseases, Al-Amal Specialist Complex, Yamamah Hospital, King Khalid Eye Specialist Hospital, King Faisal Specialist Hospital and several private clinics.

This study was conducted during the period 7/10/2013 to 7/11/2013. Besides, it accounted only for the assessment of barriers and strategies of reporting medical errors in public hospitals in Riyadh city.

\section{Results}

The data was analyzed using SPSS version19, both descriptive and inferential analyses. This study aimed at investigating the barriers and strategies of reporting medical errors in public hospitals in Riyadh city. The raised questions in this study were:

1. What are the barriers which prevent nurses and the physicians from reporting medical errors?

2. What are the strategies which could be used to encourage reporting medical errors?

3. What is the relationship between reporting of medical errors (barriers and the strategies) and sociodemographic variables?

Table (2): Socio-demographic characteristics of participants

\begin{tabular}{|c|c|c|c|}
\hline & Variables level & Frequency & Percentage \\
\hline \multirow[t]{4}{*}{ Type of hospital } & Public & 277 & 59.3 \\
\hline & Educational 121 & & 25.9 \\
\hline & Private & 69 & 14.8 \\
\hline & Total & 467 & 100.0 \\
\hline \multirow[t]{3}{*}{ Gender } & Male & 201 & 43 \\
\hline & Female & 266 & 57 \\
\hline & Total & 467 & 100.0 \\
\hline \multirow[t]{3}{*}{ Nationality } & Saudi & 204 & 43.7 \\
\hline & Non-Saudi & 263 & 56.3 \\
\hline & Total & 467 & 100.0 \\
\hline \multirow[t]{3}{*}{ Occupation } & Nurses & 273 & 58.5 \\
\hline & Physicians & 194 & 41.5 \\
\hline & Total & 467 & 100.0 \\
\hline \multirow[t]{6}{*}{ Level of education } & Diploma & 162 & 34.7 \\
\hline & Bachelors & 206 & 44.1 \\
\hline & Maser & 45 & 9.6 \\
\hline & Board & 45 & 9.6 \\
\hline & $\mathrm{PhD}$ & 9 & 1.9 \\
\hline & Total & 467 & 100.0 \\
\hline \multirow[t]{5}{*}{ Age (years) } & $20-30$ & 221 & 47.3 \\
\hline & $31-40$ & 144 & 30.8 \\
\hline & $41-50$ & 71 & 15.2 \\
\hline & 51-above & 31 & 6.6 \\
\hline & Total & 467 & 100.0 \\
\hline \multirow[t]{5}{*}{ Years' experience } & $0-10$ & 257 & 55 \\
\hline & $11-20$ & 140 & 30 \\
\hline & $21-30$ & 51 & 10.9 \\
\hline & 31 and above & 19 & 4.1 \\
\hline & Total & 467 & 100.0 \\
\hline \multirow{4}{*}{$\begin{array}{r}\text { System for reporting medical } \\
\text { errors }\end{array}$} & Yes & 259 & 55.5 \\
\hline & No & 133 & 28.5 \\
\hline & Don't know & 75 & 16.1 \\
\hline & Total & 467 & 100.0 \\
\hline
\end{tabular}

Table 2 presents the socio-demographic characteristics of the participants. It can be clearly seen that most of the participants were from public hospitals which represent $59.3 \%$ followed by educational hospitals with $25.9 \%$, then the private hospitals with $14.8 \%$. Once again, it can be noticed that most of the participants were females $57 \%$ and only $43 \%$. For males.Besides, most of the participants were non Saudi, representing $56.3 \%$ as compared to Saudi participants representing $43.7 \%$.

The nurses represented $58.5 \%$ of the whole participants as compared to $41.5 \%$ for the physicians. In terms of academic qualifications, most of the participants were those holding bachelor degrees, representing $44.1 \%$, followed by diploma holder representing $34.7 \%$, then master and board-representing $9.6 \%$ for the former and $1.9 \%$ for the latter.

In regard to age of the participants, most of the participants ages range from 20-30 years representing $47.3 \%$ followed by $31-40$ years representing $30.8 \%$ and then $41-50$ representing $15.2 \%$. The last age range was 51 years and above representing only $6.6 \%$. 
The element before the last in the socio-demographic characteristics of the participants in this study was years of experience. It shows that most of participants' years of experience is in the age range of $0-10$ years-representing $55 \%$, followed by $11-20$ years representing $30 \%$, then $21-20$ years with $10.9 \%$ and finally the age range of 31 years and above representing only $4.1 \%$.

Finally and in regard to having a system reporting medical errors, most of the respondents say that they have a reporting system for medical errors, representing $55.5 \%$ as compared to $28.5 \%$ who reported that they don't have areporting medical errors system and $16.1 \%$ for those who stated that they didn't know if there is a reporting medical errors system in their hospitals/ clinics.

\begin{tabular}{|l|l|l|l|}
\hline \multicolumn{4}{|c|}{ Table(3): Barriers preventing reporting medical errors } \\
\hline Barrier & N & Mean & Std. Deviation \\
\hline Fear of being blamed... & 467 & 3.24 & 1.248 \\
\hline Fear of being punished... & 467 & 3.22 & 1.236 \\
\hline Difficulty in filling the form... & 467 & 3.18 & 1.343 \\
\hline Lack of knowledge of what we should report... & 467 & 3.16 & 1.321 \\
\hline Medical errors reporting are inadequate... & 467 & 3.12 & 1.253 \\
\hline Lack procedures on reporting medical errors... & 467 & 3.11 & 1.347 \\
\hline Complexity of work... & 467 & 3.11 & 1.281 \\
\hline Medical errors insurance lead to decrease medical errors reporting... & 467 & 3.08 & 1.290 \\
\hline Lack of time... & 467 & 2.94 & 1.338 \\
\hline Reporting errors isn't anonymous... & 467 & 2.93 \\
\hline Some medical errors are trivial to report... & 467 & 2.92 \\
\hline Reporting errors isn't my responsibility... & 467 & 2.92 & 1.237 \\
\hline Reporting errors will not make any improvement... & 467 & 2.64 \\
\hline Reporting errors is not a priority... & 467 & 2.61 \\
\hline Valid N (list wise) & 467 & 1.377 \\
\hline
\end{tabular}

We can see from the above table (3) that the participants vary in responding to the barriers which prevent reporting the medical errors with the mean range from $\mu=3.24$ to $\mu=2.61$. The highest mean range was for fear of being blamed. On the other hand, the lowest mean was for reporting errors is not a priority. This statistical ranking could give us an initial list for barriers treatment.

\begin{tabular}{|l|l|l|l|}
\hline \multicolumn{4}{|c|}{ Table (4):Strategies improving reporting medical errors } \\
\hline & N & Mean & Std. Deviation \\
\hline There should be clear guidelines and procedures to reporting errors; & 467 & 4.49 & .716 \\
\hline Forms and other documentation should be clear; & 467 & 4.47 & .806 \\
\hline Staff should be trained on reporting medical errors; & 467 & 4.40 & .797 \\
\hline Staff should always be encouraged to report medical errors; & 467 & 4.36 & .835 \\
\hline Reporting errors should be mandatory; & 467 & 4.29 & .845 \\
\hline Staff should always be provided by feedback on what has been reported; & 467 & 4.27 & .914 \\
\hline Use computerized system; and/or & 467 & 4.09 & 1.023 \\
\hline Reporting errors shouldn't be used against reporters. & 467 & 3.95 & 1.214 \\
\hline Valid N (list wise) & 467 & & \\
\hline
\end{tabular}

In table 4 above, we can see that the participants agreed to the idea of the proposed strategies take the mean range from $\mu=3.95$ to $\mu=4.49$ indicating the possibility of using such proposed strategies towards improving the reporting of the medical errors.

Tables (5-7) show the T- test results to see if there is a significance between the participants responding to the barriers, strategies and the gender, nationality and occupations.

\begin{tabular}{l|l|l|l|l|l}
\hline \multicolumn{7}{c}{ Table(5): Gender Group Statistics } \\
\hline \multirow{2}{*}{ Barriers } & Gender & N & Mean & Std. Deviation & Std. Error Mean \\
\hline \multirow{3}{*}{ Strategies } & Male & 201 & 3.0380 & .73724 & .05200 \\
\cline { 2 - 6 } & Female & 266 & 2.9954 & .76582 & .04696 \\
\cline { 2 - 6 } & Male & 201 & 4.2948 & .67374 & .04752 \\
\cline { 2 - 6 } & Female & 266 & 4.2885 & .55958 & .03431 \\
\hline
\end{tabular}




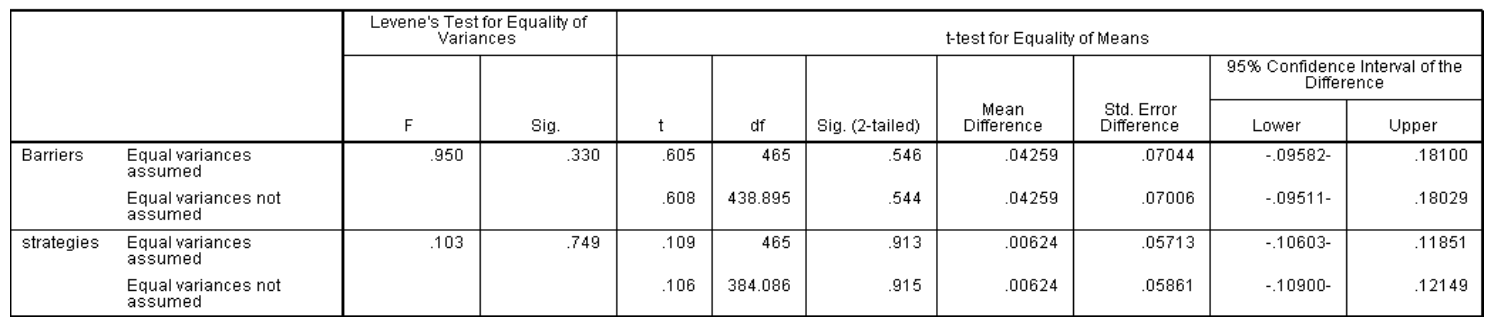

Table (5) demonstrates that there is no significance differences between the male and female regarding reporting the barriers and the strategies; $($ sig. $=.546>.05)$ and $($ sig. $=.913>.05)$

\begin{tabular}{llllll}
\hline \multicolumn{5}{c}{ Table(6): Nationality Group Statistics } \\
\hline \multirow{2}{*}{ Barriers } & Nationality & $\mathrm{N}$ & Mean & Std. Deviation & Std. Error Mean \\
& Saudi & 204 & 3.0679 & .74409 & .05210 \\
\cline { 2 - 6 } & non Saudi & 263 & 2.9718 & .75885 & .04679 \\
\hline \multirow{2}{*}{ Strategies } & Saudi & 204 & 4.3297 & .55882 & .03913 \\
& non Saudi & 263 & 4.2614 & .64749 & .03993 \\
\hline
\end{tabular}

\begin{tabular}{|c|c|c|c|c|c|c|c|c|c|c|}
\hline & & \multicolumn{2}{|c|}{$\begin{array}{l}\text { Levene's Test for Equality of } \\
\text { Variances }\end{array}$} & \multicolumn{7}{|c|}{ t-test for Equality of Means } \\
\hline & & \multirow[b]{2}{*}{$\mathrm{F}$} & \multirow[b]{2}{*}{ Sig. } & \multirow[b]{2}{*}{$\mathrm{t}$} & \multirow[b]{2}{*}{ df } & \multirow[b]{2}{*}{ Sig. (2-tailed) } & \multirow[b]{2}{*}{$\begin{array}{l}\text { Mean } \\
\text { Difference }\end{array}$} & \multirow[b]{2}{*}{$\begin{array}{l}\text { Std. Error } \\
\text { Difference }\end{array}$} & \multicolumn{2}{|c|}{$\begin{array}{l}95 \% \text { Confidence Interval of the } \\
\text { Difference }\end{array}$} \\
\hline & & & & & & & & & Lower & Upper \\
\hline \multirow[t]{2}{*}{ Barriers } & $\begin{array}{l}\text { Equal variances } \\
\text { assumed }\end{array}$ & \multirow[t]{2}{*}{.000} & \multirow[t]{2}{*}{.991} & 1.370 & 465 & .171 & .09617 & .07020 & $-.04178-$ & .23412 \\
\hline & $\begin{array}{l}\text { Equal variances not } \\
\text { assumed }\end{array}$ & & & 1.373 & 440.515 & .170 & .09617 & .07003 & $-.04145-$ & .23380 \\
\hline \multirow[t]{2}{*}{ strategies } & $\begin{array}{l}\text { Equal variances } \\
\text { assumed }\end{array}$ & \multirow[t]{2}{*}{.192} & \multirow[t]{2}{*}{.661} & 1.199 & 465 & .231 & .06825 & .05694 & $-.04365-$ & .18015 \\
\hline & $\begin{array}{l}\text { Equal variances not } \\
\text { assumed }\end{array}$ & & & 1.221 & 459.688 & .223 & .06825 & .05590 & $-.04160-$ & .17810 \\
\hline
\end{tabular}

Table (6) shows too that there is no significance differences between Saudi and non-Saudi participants in regard to the barriers and the strategies reporting; (sig. $=.170>.05$ ) and (sig.=.231>.05).

Table(7): Occupation group statistics

\begin{tabular}{llllll}
\hline \multirow{2}{*}{ Barriers } & Occupation & $\mathrm{N}$ & Mean & Std. Deviation & Std. Error Mean \\
& nurse & 273 & 2.9969 & .79400 & .04805 \\
\cline { 2 - 6 } Strategies & Physician & 194 & 3.0376 & .69291 & .04975 \\
& nurse & 273 & 4.2816 & .56655 & .03429 \\
\cline { 2 - 6 } & Physician & 194 & 4.3048 & .66909 & .04804
\end{tabular}

\begin{tabular}{|c|c|c|c|c|c|c|c|c|c|c|}
\hline & & \multicolumn{2}{|c|}{$\begin{array}{l}\text { Levene's Test for Equality of } \\
\text { Variances }\end{array}$} & \multicolumn{7}{|c|}{ t-test for Equality of Means } \\
\hline & & \multirow[b]{2}{*}{$\mathrm{F}$} & \multirow[b]{2}{*}{ Sig. } & \multirow[b]{2}{*}{ t } & \multirow[b]{2}{*}{ df } & \multirow[b]{2}{*}{ Sig. (2-tailed) } & \multirow[b]{2}{*}{$\begin{array}{c}\text { Mean } \\
\text { Difference }\end{array}$} & \multirow[b]{2}{*}{$\begin{array}{l}\text { Std. Error } \\
\text { Difiterence }\end{array}$} & \multicolumn{2}{|c|}{$\begin{array}{l}95 \% \text { Confidence Interval of the } \\
\text { Difference }\end{array}$} \\
\hline & & & & & & & & & Lower & Upper \\
\hline \multirow[t]{2}{*}{ Barriers } & $\begin{array}{l}\text { Equal variances } \\
\text { assumed }\end{array}$ & \multirow[t]{2}{*}{4.997} & \multirow[t]{2}{*}{.026} & $-.575-$ & 465 & .566 & $-.04069-$ & .07077 & $-.17977-$ & .09838 \\
\hline & $\begin{array}{l}\text { Equal variances not } \\
\text { assumed }\end{array}$ & & & $-.588-$ & 445.800 & .557 & $-.04069-$ & .06917 & $-.17663-$ & .09524 \\
\hline \multirow[t]{2}{*}{ strategies } & $\begin{array}{l}\text { Equal variances } \\
\text { assumed }\end{array}$ & \multirow[t]{2}{*}{1.912} & \multirow[t]{2}{*}{.167} & $-.404-$ & 465 & .687 & $-.02317-$ & .05739 & $-.13596-$ & .08961 \\
\hline & $\begin{array}{l}\text { Equal variances not } \\
\text { assumed }\end{array}$ & & & $-393-$ & 371.364 & .695 & $-.02317-$ & .05902 & $-.13923-$ & .09288 \\
\hline
\end{tabular}

Table (7) states that there is no significance differences between nurses and physicians in regard to the barriers and the strategies reporting; $($ sig. $=.577>.05)$ and $($ sig. $=.687>.05)$.

Tables (8-11) present ANOVA test results to see if there is a significance between the participants' responses to the barriers, strategies and the (type of the hospital, age, education level and years of experience).

Table(8): Type of hospital

\begin{tabular}{l|l|l|l|l|l|l}
\hline \multicolumn{2}{c|}{} & Sum of Squares & df & $\begin{array}{l}\text { Mean } \\
\text { Square }\end{array}$ & F & Sig. \\
\hline \multirow{3}{*}{ Barriers } & Between Groups & .829 & 2 & .415 & .730 & .482 \\
\cline { 2 - 8 } & Within Groups & 263.500 & 464 & .568 & & \\
\cline { 2 - 8 } & Total & 264.330 & 466 & & .35 & .701 \\
\hline \multirow{3}{*}{ strategies } & Between Groups & .266 & 2 & .133 & .35 \\
\cline { 2 - 8 } & Within Groups & 173.503 & 464 & .374 & & \\
\cline { 2 - 8 } & Total & 173.769 & & & \\
\hline
\end{tabular}

Table (8) clarifies that there is no significance differences between the types of the hospitals regarding the barriers and the strategies reporting; $($ sig. $=.482>.05) \quad$ and (sig. $=.701>.05)$. 


\begin{tabular}{|c|c|c|c|c|c|c|}
\hline \multicolumn{7}{|c|}{ Table (9): Age structure } \\
\hline & & Sum of Squares & df & Mean Square & $\mathrm{F}$ & Sig. \\
\hline \multirow[t]{3}{*}{ Barriers } & Between Groups & 10.252 & 3 & 3.417 & 6.227 & .000 \\
\hline & Within Groups & 254.078 & 463 & .549 & & \\
\hline & Total & 264.330 & 466 & & & \\
\hline \multirow[t]{3}{*}{ strategies } & Between Groups & 2.514 & 3 & .838 & 2.266 & .080 \\
\hline & Within Groups & 171.255 & 463 & .370 & & \\
\hline & Total & 173.769 & 466 & & & \\
\hline
\end{tabular}

\begin{tabular}{|c|c|c|c|c|c|c|c|}
\hline \multirow[b]{2}{*}{ Dependent Variable } & \multirow[b]{2}{*}{ (1) age } & \multirow[b]{2}{*}{ (J) age } & \multirow[b]{2}{*}{$\begin{array}{l}\text { Mean } \\
\text { Difference (I- } \\
J)\end{array}$} & \multirow[b]{2}{*}{ Std. Error } & \multirow[b]{2}{*}{ Sig. } & \multicolumn{2}{|c|}{$95 \%$ Confidence Interval } \\
\hline & & & & & & Lower Bound & Upper Bound \\
\hline \multirow[t]{12}{*}{ Barriers } & $20-30$ & $31-40$ & $-.14629-$ & .07933 & .335 & $-.3689-$ & .0763 \\
\hline & & $41-50$ & .25821 & .10106 & .090 & $-.0253-$ & .5418 \\
\hline & & $51 Y$ and above & .28489 & .14207 & .261 & $-.1137-$ & .6835 \\
\hline & $31-40$ & $20-30$ & .14629 & .07933 & .335 & $-.0763-$ & .3689 \\
\hline & & $41-50$ & $.40450^{*}$ & .10742 & .003 & .1031 & .7059 \\
\hline & & $51 Y$ and above & $.43118^{*}$ & .14667 & .036 & .0196 & .8427 \\
\hline & $41-50$ & $20-30$ & $-.25821-$ & .10106 & .090 & $-.5418-$ & .0253 \\
\hline & & $31-40$ & $-.40450-^{*}$ & .10742 & .003 & $-.7059-$ & $-.1031-$ \\
\hline & & $51 Y$ and above & .02668 & .15947 & .999 & $-.4208-$ & .4741 \\
\hline & $51 Y$ and above & $20-30$ & $-.28489-$ & .14207 & .261 & $-.6835-$ & .1137 \\
\hline & & $31-40$ & $-.43118-^{*}$ & .14667 & .036 & $-.8427-$ & $-.0196-$ \\
\hline & & $41-50$ & $-.02668-$ & .15947 & .999 & $-.4741-$ & .4208 \\
\hline
\end{tabular}

Table (9) demonstrates that there is a significance difference between age structures regarding the barriers reporting; (sig. $=.000<.05$ ) in which the age range between $31-40$ years has more responses to reporting the barriers than that of the age range 41-50 years, and 50 years and above.

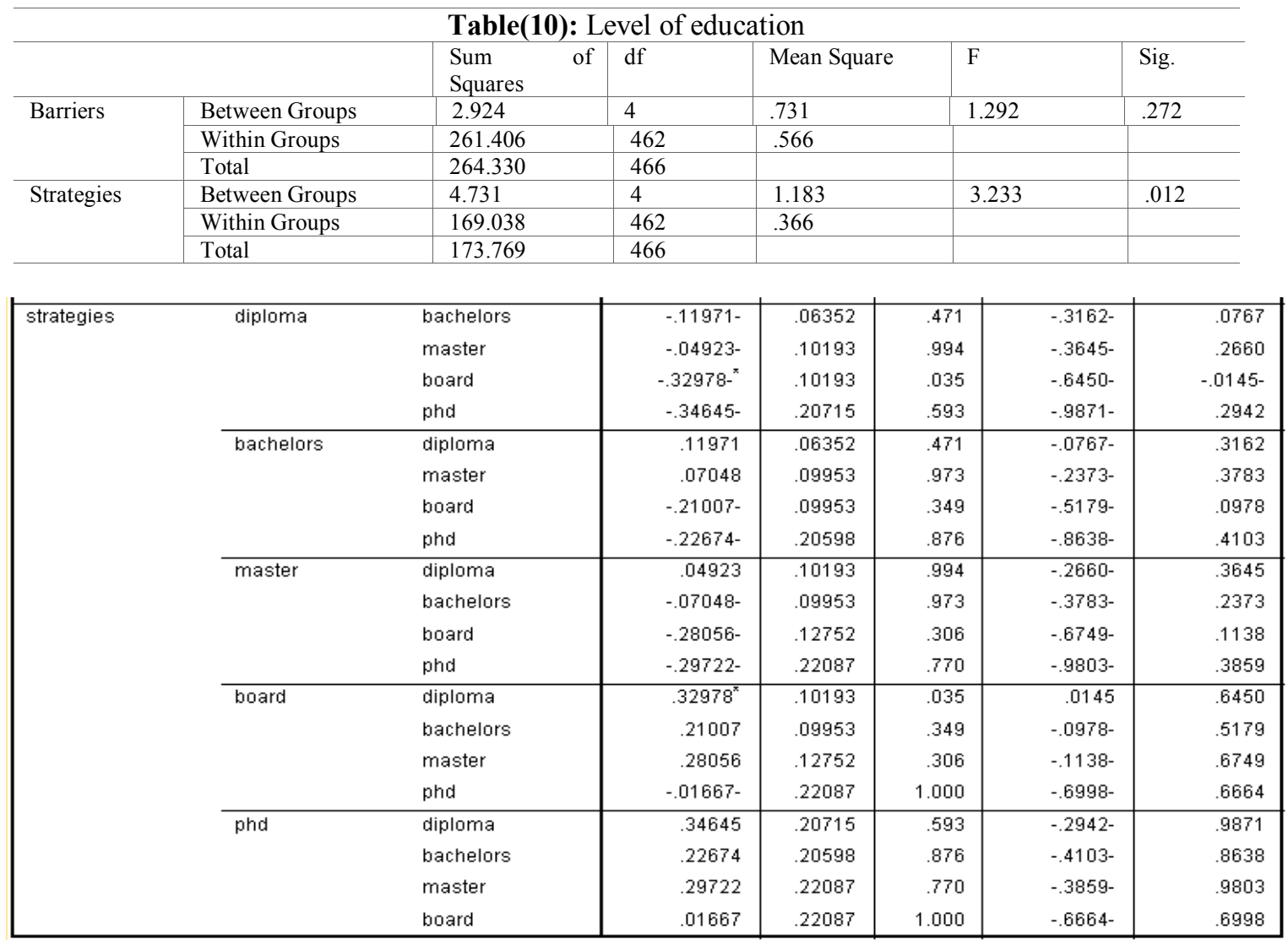

Table (10) shows that there is a significance difference between level of education regarding the strategies reporting; (sig.=.012<.05) in which the participants with board qualification have more responses to reporting the barriers than those provided by those holding the diploma qualification.

Table(11): Years of experience

\begin{tabular}{l|l|l|l|l|l|l}
\hline \multicolumn{2}{l|}{} & Sum of Squares & df & Mean Square & F & Sig. \\
\hline Barriers & Between Groups & 12.206 & 3 & 4.069 & 7.472 & .000
\end{tabular}




\begin{tabular}{l|l|l|l|l|l|l}
\hline & Within Groups & 252.124 & 463 & .545 & & \\
\cline { 2 - 7 } & Total & 264.330 & 466 & & & \\
\hline \multirow{5}{*}{ Strategies } & Between Groups & 2.349 & 3 & .783 & 2.115 & .098 \\
\cline { 2 - 7 } & Within Groups & 171.420 & 463 & .370 & & \\
\cline { 2 - 7 } & Total & 173.769 & 466 & & & \\
\hline
\end{tabular}

\begin{tabular}{|c|c|c|c|c|c|c|c|}
\hline \multirow[b]{2}{*}{ Dependent Variable } & \multirow[b]{2}{*}{ (1) years of experience } & \multirow[b]{2}{*}{ (J) years of experience } & \multirow{2}{*}{$\begin{array}{c}\text { Mean } \\
\text { Difference (I- } \\
\mathrm{J})\end{array}$} & \multirow[b]{2}{*}{ Std. Error } & \multirow[b]{2}{*}{ Sig. } & \multicolumn{2}{|c|}{$95 \%$ Confidence Interval } \\
\hline & & & & & & Lower Bound & Upper Bound \\
\hline \multirow[t]{12}{*}{ Barriers } & $0-10$ & $11-20$ & $-.04044-$ & .07751 & .965 & $-.2579-$ & .1770 \\
\hline & & $21-30$ & $.41124^{\pi}$ & .11312 & .005 & .0938 & .7286 \\
\hline & & $31 \mathrm{Y}$ and above & $.49528^{\pi}$ & .17544 & .048 & .0030 & .9875 \\
\hline & $11-20$ & $0-10$ & .04044 & .07751 & .965 & $-.1770-$ & .2579 \\
\hline & & $21-30$ & $.45168^{x}$ & .12069 & .003 & .1130 & .7903 \\
\hline & & $31 \mathrm{Y}$ and above & $.53571^{\pi}$ & .18042 & .033 & .0295 & 1.0419 \\
\hline & $21-30$ & $0-10$ & $-.41124-^{-}$ & .11312 & .005 & $-.7286-$ & $-.0938-$ \\
\hline & & $11-20$ & $-.45168-^{*}$ & .12069 & .003 & $-.7903-$ & $-.1130-$ \\
\hline & & $31 \mathrm{Y}$ and above & .08403 & .19834 & .981 & $-.4725-$ & .6405 \\
\hline & $31 Y$ and above & $0-10$ & $-.49528-^{*}$ & .17544 & .048 & $-.9875-$ & $-.0030-$ \\
\hline & & $11-20$ & $-.53571-^{*}$ & .18042 & .033 & -1.0419 & $-.0295-$ \\
\hline & & $21-30$ & $-.08403-$ & .19834 & .981 & $-.6405-$ & .4725 \\
\hline
\end{tabular}

Table (11) declares that there is a significance difference between years of experience regarding the barriers reporting;(sig.=.000<.05) in which the $0-10$ years and $11-20$ experience provided more responses to reporting the barriers than that provided by both21-30 years and 31 years and above.

\section{Discussion}

The results of this study came in agreement to our initial expectations. We conducted the study attempting to assess the barriers and the strategies for reporting the medical errors at Riyadh hospitals in Saudi Arabia.The sample of research consisted of 467 participants working in different hospitals in Riyadh and Al[Kharj] cities in Saudi Arabia.

The results indicated that most of the participants stated that they have a reporting system for medical errors, representing $55.5 \%$ as compared to only $28.5 \%$ claiming that they don't have an error-reporting system.

Actually, there are many articles which described the barriers and strategies of reporting medical errors. These include but not limited to: Hartnell (2012) in Canada, Tmrayyan (2012) in Jordon and Thomas (2010) in France.

Consider also Hashemi (2012) in his study (Factors associated with reporting nursing errors in Iran) where he reported that the most common barriers preventing reporting the medical errors include: fear of legal action and job threats, fear of economic losses, fear of honor and dignity, weakness of knowledge and weakness of nursing skills in error management.

Similarly, Chiang (2006) in his study (Barriers to Nurses' Reporting of Medication Administration Errors in Taiwan) where he showed that the most common factors preventing reporting of the medical errors are: no positive feedback for giving medication correctly and fear was considered as a major barrier.

Similar findings were also supported in previous studies by using the same study instrument (questionnaire). However, the researchers in this study found that the most common barriers preventing the staff from reporting the medical errors are:

1. Fear of being blamed;

2. Fear of being punished;

3. Difficulty in filling in the form;

4. Lack of knowledge of what should be reported;

5. Medical errors reporting is inadequate; and

6. Lack of procedures on reporting medical errors.

These findings are actually in agreement with the above stated findings in the previous studies which indicated that there is a different staff views and causes for such a problem.

To move to the second issue which is the possible strategies that might help improving reporting medical errors, it is first worth to consider McFadden's study (2006) who identified seven critical strategies for improving reporting of the medical errors system in hospitals based on a case study of four Chicago-area hospitals.

1. Pannership with stakeholders;

2. Reporting errors free of blame;

3. Open discussion of errors;

4. Cultural shift; 
5. Education and training;

6. Statistical analysis of data; and

7. System redesign.

Additionally, Frith (2012) found that increasing the number of RN hours and decreasing or eliminating LPN hours can be a strategy to improve reporting medical errors in the hospitals.

The researchers in this study found that the possible strategies for improving medical errors reporting ranked according to the responses provided by the participants of this study are:

1. There should be a clear guidelines and procedures for reporting errors;

2. Forms and other documentation should be clear;

3. Staff should be trained on reporting medical errors;

4. Staff should always be encouraged to report medical errors;

5. Reporting errors should be mandatory;

6. Staff should always be provided by feedback on what has been reported;

7. Using computerized system;and

8. Reporting errors shouldn't be used against reporters.

\section{Conclusion}

The current survey-study aimed at assessing and identifying barriers which prevent reporting medical errors and determining some strategies that might help creating effective medical errors reporting system. The study also accounted for relationship between different socio-demographic and perception toward barriers. For that matter, a self-administrated questionnaire was developed to achieve the objectives of this study, and distributed to all types of the health sectors (government, educational and private). The sample consisting of 467 from different hospital in Saudi Arabia (Riyadh, and Al-Kharj cities) were selected randomly to include both nurses and physicians. The main results of the study were:

1. There are some noticeable barriers preventing reporting of the medical errors;

2. There are also some possible strategies that might help improving reporting the medical errors in the hospitals;

3. According to the relationship(s) between the different socio-demographic characteristics of the respondents and their perceptions toward barriers and strategies of reporting medical errors, there are no significance differences between perceptions of barriers and strategies of reporting medical errors between the males and females, between the Saudi and non-Saudi participants and between the physicians and nurses;

4. There is no significance difference between the types of hospitals regarding the barriers and the strategies reporting, (sig. $=.482>.05)$ and (sig. $=.701>.05)$;

5. There is a significant difference between age structures regarding the barriers reporting, (sig. $=.000<.05$ );

6. There is a significant differences between levels of education regarding the strategies reporting,(sig. $=.012<.05)$; and

7. There is a significant difference between years of experience regarding the barriers reporting, (sig. $=.000<.05)$.

\section{Limitations and future work}

This study has the following limitations:

1. It was conducted in 7 hospitals only, so other studies should include all and/or the other hospital in Riyadh and Al-Kharj cities;

2. Another Limitation is related to methodology used in this study where the used questionnaire is not the best data collection tool. Future studies must use the interview to gather more data from both physicians and nurses;

3. Lack of cooperation from some of hospitals' directors because of the sensitivity of the study subject;

4. Time is limited to conducting such type of research; and finally

5. Another study must identify the causes of medical errors to reduce their occurrence which was actually missed in the objectives of this study.

Based on the findings of this study, the following recommendations were made:

1. Establishment of an effective medical errors reporting system;

2. Use of a computerized system for the reporting of medical errors and training the medical staff to use it;

3. The management must give the staff a feedback on what he/she can report;

4. Reporting of medical errors should be anonymous to encourage the staff at first to report them;

5. Draw the attention of the health staff about the importance of reporting medical errors;

6. Find an accessible and easy way to record medical errors to save time and effort for the staff; and

7. Further study should investigate causes of medical errors. 


\section{References}

[1] About-editors. (2014, October 12). Health. Retrieved from about.com/health/: http://www.about.com/health/

[2] Alemdar, K. D., \& Aktaş, Y. (2013). Medical Error Types and Causes Made by Nurses in Turkey. TAF Preventive Medicine Bulletin, 12(3), 307-314. doi:10.5455/pmb.1-1345816200

[3] Anderson, J. G., Ramanujam, R., Hensel, D. J., \& Sirio, C. A. (2010). Reporting trends in a regional medication error datasharing system. Health Care Management Science, 13(1), 74-83. doi:10.1007/s10729-009-9111-1

[4] Biomedcentral-editors. (2014, October 12). Health Care . Retrieved from biomedcentral.com: http://www.biomedcentral.com/content

[5] Chiang, H., \& Pepper, G. (2006). Barriers to nurses' reporting of medication administration errors in Taiwan. Journal of Nursing Scholarship, 38(4), 392-399. doi:10.1111/j.1547-5069.2006.00133.x

[6] Choir-ut-editors. (2014, October 12). Health Care. Retrieved from choir-ut.nl: http://choir-ut.nl/index.php

[7] Elhence, P., Shenoy, V., Verma, A., \& Sachan, D. (2012). Error reporting in transfusion medicine at a tertiary care centre: a patient safety initiative. Clinical Chemistry and Laboratory Medicine: CCLM / FESCC, 50(11), 1935-1943. doi:10.1515/cclm2012-0212.

[8] Forster, A., Dervin, G., Martin, C., \& Papp, S. (2012). Improving patient safety through the systematic evaluation of patient outcomes. Canadian Journal of Surgery. Journal Canadien De Chirurgie, 55(6), 418-425. doi:10.1503/cjs.007811

[9] Frith, K. H., Anderson, E., Fan, T., \& Fong, E. A. (2012). Nurse Staffing Is an Important Strategy to Prevent Medication Errors in Community Hospitals. Nursing Economic\$, 30(5), 288-294.

[10] Guffey, P., Szolnoki, J., Caldwell, J., \& Polaner, D. (2011). Design and implementation of a near-miss reporting system at a large, academic pediatric anesthesia department. Pediatric Anesthesia, 21(7), 810-814. doi:10.1111/j.1460-9592.2011.03574.x

[11] Hartnell, N., MacKinnon, N., Sketris, I., \& Fleming, M. (2012). Identifying, understanding and overcoming barriers to medication error reporting in hospitals: a focus group study. BMJ Quality \& Safety, 21(5), 361-368. doi:10.1136/bmjqs-2011000299

[12] Hashemi, F., Nasrabadi, A., \& Asghari, F. (2012). Factors associated with reporting nursing errors in Iran: a qualitative study. BMC Nursing, 11(1), 20-27. doi:10.1186/1472-6955-11-20

[13] Institute of Medicine. (2006). Preventing medication errors. Retrieved November 20, 2008, fromhttp://www.iom.edu/Object.File/Master/35/943/medication\%20errors\%20new

[14] Kagan, I., \& Barnoy, S. (2013). Organizational Safety Culture and Medical Error Reporting by Israeli Nurses. Journal of Nursing Scholarship, 45(3), 273-280. doi:10.1111/jnu.12026

[15] McDonald, K. M., Matesic, B., Contopoulos-Ioannidis, D. G., Lonhart, J., Schmidt, E., Pineda, N., \& Ioannidis, J. A. (2013). Patient Safety Strategies Targeted at Diagnostic Errors. Annals of Internal Medicine, 158381-389.

[16] McFadden, K. L., Stock, G. N., \& Gowen, C. R. (2006). Exploring Strategies for Reducing Hospital Errors. Journal Of Healthcare Management, 51(2), 123-135.

[17] Mrayyan, M. T. (2012). Reported incidence, causes, and reporting of medication errors in teaching hospitals in Jordan: A comparative study. Contemporary Nurse: A Journal for The Australian Nursing Profession, 41(2), 216-232.

[18] Mrayyan, M., Shishani, K., \& Al-Faouri, I. (2007). Rate, causes and reporting of medication errors in Jordan: nurses' perspectives. Journal of Nursing Management, 15(6), 659-670. doi:10.1111/j.1365-2834.2007.00724.x

[19] Ncbi-editors. (2014, October 12). Health Care . Retrieved from ncbi.nlm.nih.gov/: http://www.ncbi.nlm.nih.gov/

[20] Nursingeconomics-editors. (2014, October 12). Health Care . Retrieved from nursingeconomics.net: http://www.nursingeconomics.net/cgi-bin/WebObjects/NECJournal.woa

[21] Onlinelibrary-editors. (2014, October 12). Health Care . Retrieved from onlinelibrary.wiley.com: http://onlinelibrary.wiley.com/subject/code/000068

[22] Openclinical-editors. (2014, October 12). Health Care . Retrieved from openclinical.org: http://www.openclinical.org/home.html

[23] Pal, S., Duncombe, C., Falzon, D., \& Olsson, S. (2013). WHO Strategy for Collecting Safety Data in Public Health Programmes: Complementing Spontaneous Reporting Systems. Drug Safety, 36(2), 75-81. doi:10.1007/s40264-012-0014-6

[24] Phsj-editors. (2014, October 12). Health Care . Retrieved from phsj.org/: http://phsj.org/

[25] Physicians Say Medical-Error-Reporting Systems Are Inadequate. (2008). Professional Safety, 53(3), 19.

[26] Qualitydigest-editors. (2014, October 12). Health Care . Retrieved from qualitydigest.com/: http://www.qualitydigest.com/

[27] Readperiodicals-editors. (2014, October 12). Health Care. Retrieved from readperiodicals.com/: http://www.readperiodicals.com/

[28] Scopemed-editors. (2014, October 12). Health Care . Retrieved from scopemed.org/: http://www.scopemed.org/

[29] Soon, K., SO-HI, K., JIN-A, K., \& SUNHEE, C. (2011). Nurses' perceptions of medication errors and their contributing factors in South Korea. Journal of Nursing Management, 19(3), 346-353. doi:10.1111/j.1365-2834.2011.01249.x

[30] Thomas, L., Cordonnier-Jourdin, C., Benhamou-Jantelet, G., Diviné, C., \& Le Louët, H. (2011). Medication errors management process in hospital: a 6-month pilot study. Fundamental \& Clinical Pharmacology, 25(6), 768-775. doi:10.1111/j.14728206.2010.00907.x

[31] WHO-editors. (2014, October 12). Health Care. Retrieved from wo-umc.org/: http://www.who-umc.org/

\section{Appendix}

\section{Questionnaire}

\section{Dear Applicant}

We are a group of researchers at King Saud University, and some other researchers from other universities and we are conducting a research about the barriers of reporting medical errors and strategies to improve dealing with such barriers. According to your experience in the field, we would like your cooperation with us.

Please read the questionnaire and answer all the questions with the opinion that matches the current situation in Riyadh and Al-Kharj hospitals. Kindly, tick $(\checkmark)$ in the appropriate field for your point of view.

\section{Contact persons:}

If you have any enquiry about the contents of the questionnaire, don't hesitate to ask us.

Bader Al-Shabrain (0535000220) $\quad$ OR AbdullahAl-enazi (0555949300) 
Thanking you for your understanding and your cooperation with us.

Part 1:

\begin{tabular}{|c|c|c|c|c|c|}
\hline The Statement & $\begin{array}{l}\text { Strongly } \\
\text { Agree } \\
\text { (1) }\end{array}$ & $\underbrace{}_{(2)}$ & $\begin{array}{l}\text { Neutral } \\
\text { (3) }\end{array}$ & $\begin{array}{l}\text { Disagree } \\
\text { (4) }\end{array}$ & $\begin{array}{l}\text { Strongly } \\
\text { disagree } \\
(5)\end{array}$ \\
\hline \multicolumn{6}{|l|}{ 1- Lack of time } \\
\hline \multicolumn{6}{|l|}{ 2- Complexity of work } \\
\hline \multicolumn{6}{|c|}{ 3- Reporting errors isn't my responsibility } \\
\hline \multicolumn{6}{|c|}{ 4- Lack of knowledge on what we should report } \\
\hline \multicolumn{6}{|l|}{ 7- Reporting errors isn't anonymous*. } \\
\hline \multicolumn{6}{|c|}{ 8- Some medical errors are trivial to report. } \\
\hline \multicolumn{6}{|c|}{ 9- Reporting errors will not make any improvement. } \\
\hline \multicolumn{6}{|l|}{ 10- Fear of being blamed } \\
\hline \multicolumn{6}{|l|}{ 11- Fear of being punished } \\
\hline \multicolumn{6}{|c|}{$\begin{array}{l}13-\text { Medical errors insurance lead to decrease the medical errors } \\
\text { reporting. }\end{array}$} \\
\hline
\end{tabular}

- Type of the hospital: Governmental Educational Private

- Socio-demographic data:

\begin{tabular}{|c|c|c|c|c|c|}
\hline \multicolumn{6}{|l|}{ Questions } \\
\hline Gender & Male & Female & & & \\
\hline Nationality & Saudi & Non-Saudi & & & \\
\hline Occupation & Nurse & Physician & & & \\
\hline Level of education & Diploma & Bachelor & Master & Board & $\begin{array}{l}\text { Other } \\
\text { specify............ }\end{array}$ \\
\hline Age & $20-30 \mathrm{Ys}$ & $31-40 \mathrm{Ys}$ & $41-50 \mathrm{Ys}$ & 51 Ys and above & \\
\hline Years of experience & $0-10 \mathrm{Ys}$ & $11-20 \mathrm{Ys}$ & $21-30 \mathrm{Ys}$ & 31 Ys and above & \\
\hline
\end{tabular}

Part 2: In your opinion please indicate which of the following statements may be a barrier to reporting the medical errors?

*Anonymous:(not including the reporter name in the reporting process

Part3: In your opinion please indicate which of the following strategies could be used to improve the reporting medical errors?

\begin{tabular}{|l|l|l|l|l|l|}
\hline The Statement & $\begin{array}{l}\text { Strongly Agree } \\
(1)\end{array}$ & $\begin{array}{l}\text { Agreed } \\
(2)\end{array}$ & $\begin{array}{l}\text { Neutral } \\
\text { (3) }\end{array}$ & $\begin{array}{l}\text { Disagree } \\
\text { (4) }\end{array}$ & $\begin{array}{l}\text { Strongly } \\
\text { disagree } \\
(5)\end{array}$ \\
\hline 1- Use a computerized system. & & & & & \\
\hline 2- Reporting errors shouldn't be used against reporters. & & & & & \\
\hline $\begin{array}{l}\text { 3- Staff should always be encouraged to report medical } \\
\text { errors. }\end{array}$ & & & & & \\
\hline $\begin{array}{l}\text { 4- Staff should always be provided by feedback on what has } \\
\text { been reported. }\end{array}$ & & & & & \\
\hline $\begin{array}{l}\text { 5- There should be a clear guidelines and procedures for } \\
\text { reporting errors. }\end{array}$ & & & & & \\
\hline 6- Reporting errors should be mandatory. & & & & & \\
\hline 7- Staff should be trained on reporting medical errors. & & & & & \\
\hline 8- Forms and other documentation should be clear. & & & & \\
\hline
\end{tabular}

